\title{
Recent Advances in the Treatment of Neurodegenerative Diseases Based on GSH Delivery Systems
}

\author{
Ivana Cacciatore, Leonardo Baldassarre, Erika Fornasari, Adriano Mollica, \\ and Francesco Pinnen \\ Department of Drug Sciences, Faculty of Pharmacy, G. d'Annunzio University, Via dei Vestini 31, 66100 Chieti, Italy \\ Correspondence should be addressed to Ivana Cacciatore, cacciatore@unich.it
}

Received 7 February 2012; Accepted 22 March 2012

Academic Editor: Madia Trujillo

Copyright (C) 2012 Ivana Cacciatore et al. This is an open access article distributed under the Creative Commons Attribution License, which permits unrestricted use, distribution, and reproduction in any medium, provided the original work is properly cited.

\begin{abstract}
Neurodegenerative diseases, such as Parkinson's disease (PD) and Alzheimer's disease(AD), are a group of pathologies characterized by a progressive and specific loss of certain brain cell populations. Oxidative stress, mitochondrial dysfunction, and apoptosis play interrelated roles in these disorders. It is well documented that free radical oxidative damage, particularly on neuronal lipids, proteins, DNA, and RNA, is extensive in PD and AD brains. Moreover, alterations of glutathione (GSH) metabolism in brain have been implicated in oxidative stress and neurodegenerative diseases. As a consequence, the reduced GSH levels observed in these pathologies have stimulated a number of researchers to find new potential approaches for maintaining or restoring GSH levels. Unfortunately, GSH delivery to the central nervous system (CNS) is limited due to a poor stability and low bioavailability. Medicinal-chemistry- and technology-based approaches are commonly used to improve physicochemical, biopharmaceutical, and drug delivery properties of therapeutic agents. This paper will focus primarily on these approaches used in order to replenish intracellular GSH levels, which are reduced in neurodegenerative diseases. Here, we discuss the beneficial properties of these approaches and their potential implications for the future treatment of patients suffering from neurodegenerative diseases, and more specifically from PD and AD.
\end{abstract}

\section{Introduction}

Neurodegenerative diseases such as Alzheimer's, Parkinson's, and Huntington's diseases and amyotrophic lateral sclerosis make up a group of pathologies characterized by a separated etiology with distinct morphological and pathophysiological features. These disorders are defined by a multifactorial nature and have common neuropathological hallmarks such as (a) abnormal protein dynamics with defective protein degradation and aggregation; (b) oxidative stress and free radical formation; (c) impaired bioenergetics and mitochondrial dysfunctions; (d) neuroinflammatory processes $[1,2]$. It is difficult to establish the correct sequence of these events, but it has been shown that the oxidative damage to the brains of affected individuals is one of the earliest pathological markers. Oxidative and nitrosative stresses arise from the imbalance between the increased production of both the reactive oxygen species (ROS) and the reactive nitrogen species (RNS) and the cellular antioxidant defense systems [3]. At low levels, ROS function as signaling intermediates for the modulation of cellular activities but, at higher concentrations, they contribute to neuronal membrane damage. The ROS mainly involved in neurodegeneration are the superoxide anion $\left(\mathrm{O}_{2}^{-}\right)$, the hydrogen peroxide $\left(\mathrm{H}_{2} \mathrm{O}_{2}\right)$, and the hydroxyl radical $\left(\mathrm{HO}^{\bullet}\right)$. RNS, such as nitric oxide $(\mathrm{NO})$, can react with $\mathrm{O}_{2}{ }^{-}$to produce peroxynitrite $\left(\mathrm{ONOO}^{-}\right)$, a powerful oxidant that may decompose itself to form $\mathrm{HO}^{*}$ [4]. Cells normally employ a number of defense mechanisms against free radical such as enzymes $(\mathrm{Cu} / \mathrm{Zn}$ - and $\mathrm{Mn}$ superoxide dismutase, GSH peroxidase, GSH reductase, catalase, and methionine sulfoxide reductase) and lowmolecular-weight antioxidants (vitamin E, ascorbate, and GSH) [5]. Macromolecules such as lipids, proteins, and DNA undergo damage and subsequently cell death mainly 
by apoptosis when the antioxidant defense network is not sufficient [6].

\section{GSH Depletion in PD and AD}

The brain is especially vulnerable to free radical damage because of its high oxygen consumption rate, high content of lipids, and relative paucity of antioxidant enzymes compared with other organs [7]. Significant biological changes, related to a condition of oxidative stress, have been found in brain tissue of individuals affected by PD, $\mathrm{AD}$, and other diseases $[5,8-11]$. In particular, data from postmortem studies of brains from patients with PD suggest that oxidative stress plays a role in neural degeneration of the pigmented dopaminergic neurons in the substantia nigra pars compacta (SNpc) [12]. The normal metabolism of dopamine can generate free radicals and other ROS. Furthermore, in the human $\mathrm{SNpc}$ the autooxidation of dopamine leads to neuromelanin and can generate quinone and semiquinone species and ROS [13]. Finally, enzymatic oxidation of dopamine catalyzed by monoamine oxidase leads to formation of $\mathrm{H}_{2} \mathrm{O}_{2}$, which can react with $\mathrm{Fe}^{2+}$ and form the highly reactive radical $\mathrm{HO}^{\bullet}$ via the Fenton reaction [14]. All these unfavorable events contribute to alter the antioxidant defenses suggesting that the oxidative stress plays an important role in PD. The strongest alteration in the antioxidant defense is a decrease in GSH concentration [1517]. According to postmortem studies, GSH levels in the SNpc of PD patients are remarkably lower than those of healthy subjects (60\% compared to control subjects) while oxidized glutathione (GSSG) levels are slightly increased [18, 19]. Although GSH is not the only antioxidant molecule reported to be altered in PD, it is hypothesized that the magnitude of its depletion is the earliest indicator of nigrostriatal degeneration [20]. Moreover, striatal DA content and GSH levels are not altered in areas of the brain other than $\mathrm{SNpc}$, or in other diseases affecting dopaminergic neurons [2124]. GSH loss in PD is also accompanied by a reduction in mitochondrial complex I activity, which is regionally selective for the SNpc in PD and does not occur in related basal ganglia degenerative disorders [25]. These findings suggest that decreased nigrostriatal GSH levels can initiate or facilitate a cascade of further oxidative stress with consequent degeneration of dopaminergic neurons in idiopathic PD $[26,27]$.

$\mathrm{AD}$ is characterized by the loss of pyramidal neurons in the hippocampus and cortex, as well as cholinergic neurons in the basal forebrain. The etiology of $\mathrm{AD}$ is not completely known yet, although there are different hallmarks that seem to play significant roles in the disease, such as $\beta$-amyloid $(\mathrm{A} \beta)$ deposits, $\tau$-protein aggregation, oxidative damage in cellular structures, and low levels of acetylcholine (ACh) $[28,29]$. In $A D$ patients there is a strong evidence that $A \beta-$ associated free radicals and the resultant oxidative stress are a part of the mechanism that is involved in the pathogenic cascade that leads to neurodegeneration in $\mathrm{AD}$ brain [30]. Furthermore, alterations to GSH metabolism have been found in these pathological conditions [16]. In this context,
Gu et al. [31] reported that GSH levels are depressed in $\mathrm{AD}$ cingulated cortex and $\mathrm{AD}$ substantia innominata, while Liu et al. [32] found these reduced levels only in red blood cells of male AD patients. Nevertheless, increased GSH levels have been observed by Adams et al. [33] in the midbrain and in the caudate nucleus, while normal GSH contents have been determined by Perry et al. [34]. Presumably, dissenting results are due to differences in techniques or difficulty in sample collection after death of AD patients. In any case, it has been observed that GSH protects cultured neurons against oxidative damage resulting from $\beta$-peptide and 4-hydroxynonenal (HNE), a lipid peroxidation product that is increased in $\mathrm{AD}$ [35]. A significant decrease in $\mathrm{Cu}$ and significant increases in $\mathrm{Zn}$ and $\mathrm{Fe}$ were found in $\mathrm{AD}$ hippocampus and amygdale, while $\mathrm{Cu}, \mathrm{Fe}$, and $\mathrm{Zn}$ are elevated in senile plaques of $\mathrm{AD}$. These metal ions can catalyze free radical reactions and contribute to oxidative damage observed in AD brain [36]. GSH protects these areas through formation of metal complexes via nonenzymatic reactions and may also be beneficial for normalizing the adverse effects of iron accumulation in the aging brain [37].

\section{Antioxidant Neuroprotection in PD and AD}

Neuroprotective antioxidants are considered a promising approach to slow down the progression and limit the extent of neuronal cell loss in neurodegenerative disorders [38-41]. These agents were classified by Behl and Moosmann according to their mode of action in (a) compounds that prevent the formation of free radicals; (b) compounds that chemically interfere with formed free radicals; (c) compounds which limit the damage extent to the cell by alleviating the secondary metabolic burden of increased levels of free radicals [42]. N-acetylcysteine, lipoic acid, GSH, and its thiol derivatives belong to the last class of neuroprotective antioxidants. In this context, the GSH system is especially important for cellular defense against ROS in brain cells, acting directly in detoxification of radicals in non-enzymatic reactions and working as a substrate for various peroxidases [43]. Astrocytes appear to play a key role in the GSH metabolism in the brain since astroglial GSH export is essential for providing GSH precursor to neurons. Normally astrocytes release GSH and protect it against oxidation by releasing a protecting factor into the medium. Astroglial release of GSH is the first step in the supply of the GSH precursor cysteine to neurons. The extracellular GSH is processed by $\gamma$-glutamyl transpeptidase $(\gamma$-GT) and aminopeptidase $\mathrm{N}$ $(\mathrm{ApN})$ to generate the cysteine, which limits the synthesis of GSH in neurons. Alterations of the release rate of GSH from astrocytes and reduced activities of the ectoenzymes may contribute to a lowered antioxidant defense in neurons and to an increased susceptibility to oxidative stress, both involved in the progression of neurodegenerative diseases [44]. Alterations of GSH metabolism in brain have been found in neurodegenerative disorders as $\mathrm{PD}$ and $\mathrm{AD}[5,45-$ 47]. The causes of GSH depletion are not well understood yet, but their consequences are quite serious. GSH depletion can inhibit complex I, E1 ubiquitin ligase, and proteasome activity; it can also exacerbate oxidative stress and activate 
the JNK pathway, leading to an inflammatory response. All these effects cause dopaminergic neuronal death and accumulation of proteins into Lewy bodies in patients affected by PD [48]. Furthermore, an emerging evidence indicates that the total antioxidant capacity (including GSH, ascorbic acid, uric acid, and bilirubin) has shown to be reduced by $24 \%$ in plasma samples from AD patients [49]. An increased number of mutations in mitochondrial DNA have been found in $\mathrm{AD}$, such as increased concentrations of 8-hydroxy-2-deoxyguanosine, a marker of oxidative damage to DNA. These deletions or point mutations, which may result from oxidative stress, can cause mitochondrial dysfunction and trigger apoptotic cell death. In addition to DNA damage, several mitochondrial key enzymes involved in ROS detoxification are also affected. In vivo studies on animal models of $\mathrm{AD}$ have also shown the implication of mitochondria in the disease pathogenesis [50]. In this regard, several groups have focused their efforts on developing neuroprotective strategies targeting mitochondria. Some of the major mitochondrial targets used as therapeutics against ROS-mediated damage are members of the quinone family. An ubiquinone derivative, mitoquinone mesylate or MitoQ, has been used to prevent oxidative damage in $\mathrm{AD}$ [51]. MitoQ consists of CoQ10 linked to a triphenylphosphonium ion, which has a positive charge; therefore, it accumulates in mitochondria, which have a strongly negative membrane potential (about $-120 \mathrm{mV}$ ). More precisely, MitoQ is adsorbed in the inner mitochondrial membrane facing the matrix. This ROS-enriched region provides a real potency to MitoQ. In addition, MitoQ prevents AD-like pathology in mouse cortical neurons in cell culture, attenuates $\beta$-amyloidinduced neurotoxicity, and prevents increased production of ROS.

Mitochondrial dysfunction, oxidative stress, glutamate excitotoxicity, and formation of high-molecular-weight aggregates also define the most common adult-onset motoneuron disease: amyotrophic lateral sclerosis (ALS) caused by the progressive degeneration of moto-neurons in the spinal cord, brain stem, and motor cortex [52]. Dominant mutation in $\mathrm{Cu} / \mathrm{Zn}$-superoxide dismutase (SOD1) causes familial forms of ALS. In order to investigate the role of GSH in this pathology, knockout mice for the glutamate-cysteine ligase modifier (GCLM) subunit were used. Results suggested that the lack of GCLM significantly accelerates disease and mitochondrial pathology in hSOD1 mice [53].

A promising therapeutic intervention in the above reported diseases could be the antioxidant neuroprotection [54]. In this context, the increase of GSH availability in neurons is a logical therapeutical target in neural impairment related to oxidative stress. Due to the difficulty in elevating GSH directly as described by Zeevalk et al. [55], other strategies to raise brain levels of this antioxidant have been investigated [56]. In this paper we will focus on the medicinal chemistry and technological approaches aimed at maintaining or restoring GSH levels in $\mathrm{PD}$ and $\mathrm{AD}$ patients. Particular attention will be paid to different strategies for increasing GSH levels by supplying GSH codrugs and GSH nanocarrier systems able to cross the cellular membrane more easily than GSH.

\section{Medicinal-Chemistry-Based Strategies to Increase GSH Levels}

Medicinal-chemistry-based strategies include analogues [57, 58], as well as prodrugs and codrugs approaches [59]. While each of these strategies may be equally promising to increase GSH levels, this paper will mainly focus on codrugs approach since the other medicinal-chemistrybased strategies have been previously discussed [56, 60$62]$. The codrug approach consists in linking, via a covalent chemical linkage, two different pharmacophores with similar or different pharmacological activities in order to improve physiochemical, biopharmaceutical, and drug delivery properties of therapeutic agents. The resulting codrug has to be stable at gastrointestinal level and transported to the target site of action where it provides the two parent drugs following hydrolysis [63].

The codrug approach has been used for the treatment of $\mathrm{PD}$ and $\mathrm{AD}$ joining antioxidant or chelating molecules with a therapeutic compound (antiparkinson or anti-alzheimer's drugs) [64-66]. In particular, codrugs containing antioxidant molecules such as GSH, $\mathrm{N}$-acetyl-cysteine, methionine, and cysteinyl derivatives have been synthesized in order to permit a targeted delivery of antioxidant directly to specific groups of neurons where cellular stress is associated with $\mathrm{PD}$ and $\mathrm{AD}$. The dual advantage of these antioxidant molecules lies in the fact that the antioxidant portion, in addition to acting as a scavenger directly or indirectly of free radicals, can be used as a carrier. In fact, GSH and cysteinyl derivatives can be used as BBB shuttles for delivery of antiparkinson or ant-Ialzheimer's drugs since the presence of GSH transporters at the BBB is well documented $[67,68]$. In this context, the research of new codrugs for the treatment of $\mathrm{PD}$ and $\mathrm{AD}$ has gained our attention. L-Dopa-GSH codrugs (LD-GSH, 1-2), obtained via an amide bond between LD and the C- and N-terminal GSH, respectively, have been synthesized and evaluated as potential anti-Parkinson agents with antioxidant properties (Figure 1) [69]. These codrugs permit a targeted delivery of GSH directly to SNpc neurons of PD patients and contribute in attenuating the damage caused by the prooxidant effects of traditional LD therapies. Codrugs 1-2 showed good stability toward gastrointestinal simulated fluids and released LD in rat and human plasma after enzymatic hydrolysis. Furthermore, they prolonged the plasma LD levels and were able to induce sustained delivery of dopamine (DA) in rat striatum with respect to equimolar dose of LD. Taken together, these results demonstrated the possible therapeutic application of codrugs 1-2 in PD, being able to protect against the oxidative stress deriving from autoxidation and the MAO-mediated metabolism of DA [69].

Later, More and Vince [70] reported two GSH bioconjugates (3-4) containing a metabolically stable urea analogue of GSH resistant to the enzyme $\gamma$-GT (Figure 2). The antioxidant portion has been covalently joined to the therapeutic drugs, as DA and adamantine, via a heterodisulfide linkage. This suitable junction is stable in plasma and able to release DA or adamantine, and the antioxidant portion due to the abundance of the enzyme disulfide reductases in the 
<smiles>CCCN[C@@H](CC)C(=O)OCC(=O)N[C@@H](CS)C(=O)NCC(=O)N[C@@H](Cc1ccc(O)c(O)c1)C(=O)O</smiles>

1<smiles>CC(=O)CNC(=O)[C@H](CS)NC(=O)CC[C@H](NC(=O)[C@H](N)Cc1ccc(O)c(O)c1)C(C)=O</smiles>

2

FIgURE 1: Chemical structures of GSH codrugs 1-2.

brain [71]. More importantly, these bioconjugates cross the $\mathrm{BBB}$ through recognition by GSH transporters on the luminal side of BBB [68]. Studies successfully confirmed the carrier-mediated transport of conjugates 3-4 in an in vitro $\mathrm{BBB}$ model and their ability to release the active drug at the target site, thus representing an innovative approach for the targeted delivery of anti-Parkinson drugs into the CNS using the GSH transport system [70]. In particular, the MDCK cell monolayer has been used to study the bioconjugates 3-4 transport. At concentration of $100 \mu \mathrm{M}$, the transport of bioconjugates 3-4 from the apical to the basal side was greater than the transport in the reverse direction. Moreover, to ensure that the codrugs 3-4 were not being metabolized as they crossed the MDCK cell monolayer, the integrity of codrugs 3-4 was confirmed by HPLC studies [70]. These experiments successfully demonstrated the GSHcarrier-mediated transport of the bioconjugates 3-4 in an in vitro BBB model.

Another bioconjugate that could use the GSH transporters on the luminal side of $\mathrm{BBB}$ might be the hybrid 5 (Figure 3). This molecule is characterized by the replacement of cysteine with methionine in order to obtain stable GSH analogue at $\gamma$-GT [72]. Furthermore, the GSH analogue has been linked to LD to obtain CNS drug delivery. This compound was demonstrated to cross unaltered the acidic environment of the stomach, to be stable enough to be absorbed from the intestine, to have radical scavenging activity, and to release LD in human plasma after enzymatic hydrolysis. Taken together, these data suggest a therapeutic potential of 5 in pathological events associated with free radical damage and decreasing DA concentration in the brain [72].

Recently, Ehrlich et al. [73] designed and synthesized a library of new GSH codrugs (called UPF peptides) with powerful hydroxyl radical scavenging activities. They have been obtained via an amide bond between GSH and tyrosine derivatives as shown in Figure 4. In particular, the enzyme free hydroxyl radical scavenging assay showed that substitution of $\gamma$-glutamyl moiety (UPF1, 4-methoxy-L-tyrosinyl- $\gamma$-L-glutamyl-L-cysteinyl-glycine, 6) with $\alpha$-glutamyl moiety (UPF17, 4 -methoxy-L-tyrosinyl- $\alpha$ L-glutamyl-L-cysteinyl-glycine, 7) improved hydroxyl radical scavenging activity of about 500-fold [74]. UPF1 (6) is an effective and potential agent that diminishes neuronal injury in global cerebral ischemia [75]; it acts as a free radical scavenger or a modulator of G-protein in frontocortical membrane preparations. Although the exact mechanisms of the protective action of UPF1 still remain unclear, it can possibly act as a scavenger or a signal molecule increasing GSH levels or the GSH redox ratio; UPF1 could be a promising lead for the design of powerful antioxidants for the treatment of conditions associated with reduced GSH levels [76]. Unfortunately, the role of UPF peptides for the treatment of PD has not been studied yet. It could be interesting to investigate the activity of UPF peptides in patients affected by PD since these peptides contain the tyrosine moiety, the metabolic precursor of DA.

Few data are available in the literature about GSH codrugs for the treatment of AD. We recently synthesized Ibuprofen-GSH (IBU-GSH, 8) obtained via amide bond between GSH and IBU, a nonsteroidal anti-inflammatory drug (NSAID) (Figure 5) [77]. NSAIDs treatment reduces $\mathrm{AD}$ risk, delays disease progression, and reduces microglia activation [78]. In particular, Lim et al. [79] reported that six months of treatment of a transgenic animal model of $\mathrm{AD}$ with IBU resulted in a significant reduction of amyloid plaque burden and total $\mathrm{A} \beta$ peptide levels. Furthermore, IBU treatment led to a reduction of plaque-associated microglia and a corresponding attenuation in proinflammatory cytokine levels in brain [80]. Codrug 8 possessed good stability toward human plasma enzymatic activity and displayed in vitro free radical scavenging activity in timeand concentration-dependent manner. More importantly, it antagonizes the deleterious and cognitive effects of $\beta$ amyloid(1-40) in a rat model for $\mathrm{AD}$, as also confirmed by behavioral tests of long-term spatial memory. In conclusion, IBU-GSH might permit targeted delivery of IBU and GSH directly to neurons, where oxidative stress and inflammatory processes are associated with AD [77].

Almost all the codrugs (1-2, 5, 9-14) have been tested for their chemical and enzymatic stabilities in order to check both their stability in aqueous medium and their sensitivity towards enzymatic cleavage in rat and human plasma (Tables 1 and 2) [69, 72, 81]. Stability studies were performed at $37^{\circ} \mathrm{C}$ in isotonic sodium phosphate buffer ( $\left.\mathrm{pH} 7.4\right)$, in simulated gastric fluid (SGF, pH 1.3), and in rat and human plasma diluted to $80 \%$ with isotonic sodium phosphate buffer ( $\mathrm{pH}$ 7.4). All codrugs showed good stability toward gastrointestinal hydrolysis $\left(t_{1 / 2}>20 \mathrm{~h}\right.$ ) (Table 1$)$. On the contrary, in rat and human plasma the codrugs (1-2, 5, 914) underwent rapid bioconversion of the codrugs into their constituents (Table 2).

Sulfur-containing amino acids have gained great attention as source of thiols for GSH synthesis [82]. A series of multifunctional thiol codrugs (9-14) were synthesized to overcome the prooxidant effect associated with LD 
<smiles>N[C@@H](CNC(=O)N[C@@H](CSSCC(=O)C(=O)NCCc1ccc(O)c(O)c1)C(=O)NCC(=O)O)C(=O)O</smiles><smiles>N[C@@H](CNC(=O)N[C@@H](CSSCC(=O)C(=O)NC1C2CC3CC(C2)CC1C3)C(=O)NCC(=O)O)C(=O)O</smiles>

4

FIgURE 2: Chemical structures of GSH codrugs 3-4.

TABLE 1: Kinetic data for chemical hydrolysis of codrugs $\mathbf{1 - 2 , 5}$, and 9-14 at $37^{\circ} \mathrm{C}$.

\begin{tabular}{lcccc}
\hline & \multicolumn{2}{c}{$\mathrm{pH} 1.3^{\mathrm{a}}$} & \multicolumn{2}{c}{$\mathrm{pH} 7.4^{\mathrm{a}}$} \\
Compd & $t_{1 / 2}(\mathrm{~h})$ & $K_{\mathrm{obs}}\left(\mathrm{h}^{-1}\right)$ & $7.22( \pm 0.31)$ & $0.096\left( \pm 4.1 \times 10^{-3}\right)$ \\
$\mathbf{1}$ & $20.14( \pm 0.73)$ & $0.034\left( \pm 1.2 \times 10^{-3}\right)$ & $12.23( \pm 0.49)$ & $0.057\left( \pm 2.3 \times 10^{-3}\right)$ \\
$\mathbf{2}$ & $28.12( \pm 1.21)$ & $0.025\left( \pm 1.1 \times 10^{-3}\right)$ & $10.80( \pm 0.40)$ & $0.018\left( \pm 0.8 \times 10^{-3}\right)$ \\
$\mathbf{5}$ & $20.67( \pm 0.83)$ & $0.094\left( \pm 0.3 \times 10^{-3}\right)$ & $46.2( \pm 0.90)$ & $0.015\left( \pm 0.3 \times 10^{-3}\right)$ \\
$\mathbf{9}$ & $301.0( \pm 10.5)$ & $0.002\left( \pm 0.07 \times 10^{-3}\right)$ & $48.0( \pm 1.70)$ & $0.015\left( \pm 0.45 \times 10^{-3}\right)$ \\
$\mathbf{1 0}$ & $290.6( \pm 5.8)$ & $0.002\left( \pm 0.04 \times 10^{-3}\right)$ & $30.2( \pm 1.40)$ & $0.023\left( \pm 1.04 \times 10^{-3}\right)$ \\
$\mathbf{1 1}$ & $296.3( \pm 11.8)$ & $0.002\left( \pm 0.08 \times 10^{-3}\right)$ & $26.9( \pm 0.70)$ & $0.026\left( \pm 0.65 \times 10^{-3}\right)$ \\
$\mathbf{1 2}$ & $292.1( \pm 4.4)$ & $0.002\left( \pm 0.03 \times 10^{-3}\right)$ & $48.50( \pm 0.70)$ & $0.005\left( \pm 0.25 \times 10^{-3}\right)$ \\
$\mathbf{1 3}$ & $292.8( \pm 8.8)$ & $0.002\left( \pm 0.06 \times 10^{-3}\right)$ & $21.3( \pm 0.60)$ & $0.033\left( \pm 0.99 \times 10^{-3}\right)$ \\
$\mathbf{1 4}$ & $293.4( \pm 14.7)$ & $0.002\left( \pm 0.1 \times 10^{-3}\right)$ &
\end{tabular}

${ }^{a}$ Values are means of three experiments, and standard deviation is given in parentheses.

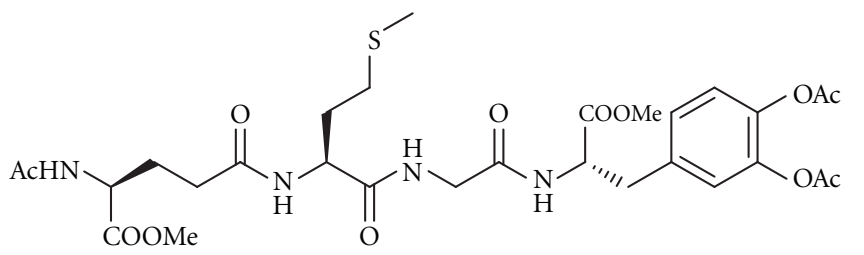

5

FIGURE 3: Chemical structure of GSH hybrid 5.

therapy in parkinsonian models (Figure 6) [81]. In this regard, thiol antioxidants ( $\mathrm{N}$-acetyl-L-cysteine, methionine, dithiothreitol) prevent DA autoxidation, production of dopamine-melanin, and inhibition of dopamine-induced apoptosis [83]. Moreover, they increase levels of intracellular cysteine, the limiting amino acid in GSH biosynthesis, thus potentiating the natural cellular defense mechanisms against oxidative damage. The multifunctional codrugs 9-14 proved to be good radical scavengers. The LD and DA striatal level profiles indicate that codrugs $\mathbf{1 1}$ and $\mathbf{1 2}$ were able to induce sustained delivery of both LD and DA in rat striatum with respect to equimolar doses of $\mathrm{LD}$ [82].

In addition, Minelli et al. [84] showed that administration of codrug 11 to mice treated with Z-ILeu-Glu(OtBu)Ala-Leu-CHO (PSI), used as a PD model, resulted in a reduction in dopaminergic neuronal death and a significant raise in GSH levels. In particular, codrug 11 could control the LD-induced oxidative stress in primary mesencephalic cultures and in newborn mice pups since in both cases GSH content results increased. Using newborn mice pups, characterized by incomplete formation of BBB, Minelli et al. [84] found that buthionine-[S,R]-sulfoximine-(BSO-) mediated GSH depletion prevented the increase of GSH levels promoted by codrug 11, supporting the role of GSH for codrug-11-induced protection. To investigate whether heme oxygenase $(\mathrm{HO})$ activity was related to $\mathrm{GSH}$ levels, ZnPPIX was used as $\mathrm{HO}$ inhibitor. Compared to untreated control, and LD-treated newborn mice, brain GSH levels were increased by ZnPPIX indicating that $\mathrm{HO}$ activity was not essential to GSH synthesis. An injection of codrug 11 induced a significant increase in GSH levels that was markedly reduced by BSO indicating the essential role of $\gamma$ glutamylcysteine synthetase in increasing GSH brain levels. Codrug 11 exhibited in vivo protective effect against LDinduced stress through a mechanism via $\mathrm{Nrf} 2$ activation leading to a decrease in ROS generation and an increase in GSH. Therefore, this codrug might offer benefits in the treatment of $\mathrm{PD}$ and provide a potential alternative to LD therapy by avoiding nigrostriatal oxidative degeneration [84].

Maher et al. [85, 86] demonstrated that the conjugation of catechins with cysteine generates antioxidant compounds (15-20) with enhanced neuroprotective activity (Figure 7). The thiol conjugates $\mathbf{1 5 - 2 0}$ were active in protecting HT22 nerve cells ( $\mathrm{EC}_{50}$ between 36 and $65 \mu \mathrm{M}$ ) from oxidative 
<smiles>COc1ccc(C[C@H](N)C(=O)N[C@@H](CCC(=O)N[C@@H](CS)C(=O)NCC(=O)O)C(=O)O)cc1</smiles>

6<smiles>COc1ccc(C[C@H](N)C(=O)N[C@@H](CCC(=O)O)C(=O)N[C@@H](CS)C(=O)NCC(=O)O)cc1</smiles>

7

FIgURE 4: Chemical structures of GSH codrugs 6-7.

TABLE 2: Rate constants for the hydrolysis of codrugs $\mathbf{1 - 2 , 5}$, and $\mathbf{9 - 1 4}$ in $80 \%$ rat plasma and $80 \%$ human plasma at $37^{\circ} \mathrm{C}$.

\begin{tabular}{lcccc}
\hline & \multicolumn{2}{c}{ Rat plasma $^{\mathrm{a}}$} & \multicolumn{2}{c}{ Human plasma $^{\mathrm{a}}$} \\
Compd & $t_{1 / 2}(\mathrm{~min})$ & $K_{\mathrm{obs}}\left(\mathrm{min}^{-1}\right)$ & $t_{1 / 2}(\min )$ & $K_{\mathrm{obs}}\left(\mathrm{min}^{-1}\right)$ \\
\hline $\mathbf{1}$ & immediate hydrolysis & - & $3.2( \pm 0.1)$ & $0.217\left( \pm 6 \times 10^{-3}\right)$ \\
$\mathbf{2}$ & $2.7( \pm 0.1)$ & $0.257\left( \pm 8 \times 10^{-3}\right)$ & $15.1( \pm 0.4)$ & $0.046\left( \pm 1 \times 10^{-3}\right)$ \\
$\mathbf{5}$ & $4.7( \pm 0.1)$ & $0.150( \pm 0.01)$ & $7.3( \pm 0.3)$ & $0.100( \pm 0.01)$ \\
$\mathbf{9}$ & $46.8( \pm 1.4)$ & $0.010\left( \pm 0.20 \times 10^{-3}\right)$ & $69.6( \pm 1.4)$ & $0.015\left( \pm 0.44 \times 10^{-3}\right)$ \\
$\mathbf{1 0}$ & $36.6( \pm 1.6)$ & $0.019\left( \pm 0.85 \times 10^{-3}\right)$ & $65.4( \pm 1.6)$ & $0.011\left( \pm 0.26 \times 10^{-3}\right)$ \\
$\mathbf{1 1}$ & $115.2( \pm 11.0)$ & $0.002\left( \pm 0.07 \times 10^{-3}\right)$ & $315.0( \pm 4.6)$ & $0.006\left( \pm 0.24 \times 10^{-3}\right)$ \\
$\mathbf{1 2}$ & $93.0( \pm 10.2)$ & $0.003\left( \pm 0.17 \times 10^{-3}\right)$ & $263.4( \pm 1.9)$ & $0.007\left( \pm 0.14 \times 10^{-3}\right)$ \\
$\mathbf{1 3}$ & $55.8( \pm 10.5)$ & $0.003\left( \pm 0.11 \times 10^{-3}\right)$ & $203.4( \pm 0.6)$ & $0.030( \pm 0.75 \times 10-3)$ \\
$\mathbf{1 4}$ & $69.6( \pm 3.5)$ & $0.010\left( \pm 0.50 \times 10^{-3}\right)$ & $90.0( \pm 2.7)$ & $0.008\left( \pm 0.24 \times 10^{-3}\right)$ \\
\hline
\end{tabular}

${ }^{a}$ Values are means of three experiments, standard deviation is given in parentheses.<smiles>CC(=O)CNC(=O)[C@H](CS)NC(=O)CC[C@H](NC(=O)C(C)c1ccc(CC(C)C)cc1)C(C)=O</smiles>

8

FIGURE 5: Chemical structure of GSH codrug 8.

stress-induced death. Although all the conjugates were able to scavenge mitochondrial generated ROS inside the cells, the majority of their neuroprotective activity seems to be dependent on their ability to maintain GSH levels. These compounds were able to maintain cellular GSH levels by enhancing the uptake of cystine/cysteine into cells by a mechanism that uncouples the uptake from system $x_{c}^{-}$, a $\mathrm{Na}^{+}$-independent cystine/glutamate antiporter [87]. System $x_{c}^{-}$transports cysteine into cells in a $1: 1$ exchange with glutamate. The importance of this system for the maintenance of the GSH levels in cells is demonstrated by the loss of GSH and subsequent cell death in nerve and other types of cells following exposure to millimolar concentrations of extracellular glutamate. Treatments able to maintain GSH levels, in presence of an induced stress by GSH loss, have a significant potential for the treatment of neurodegenerative diseases.

\section{Technology-Based Strategies to Increase GSH Levels}

The effectiveness of exogenous antioxidants to protect tissues from oxidative stress in vivo depends on the antioxidant used, its physicochemical and biopharmaceutical properties, and its bioavailability at the site of action $[88,89]$. With the aim of improving the physicochemical, biopharmaceutical and drug delivery properties of neuroprotective antioxidants, the technology-based strategy could be useful for the treatment of several diseases in which oxidative stress plays an important role [59, 90]. Particularly, this approach could be adopted in order to selectively deliver antioxidants to tissues in sufficient concentrations to reduce the oxidative damage. In order to afford neuroprotection and to facilitate the delivery of GSH across the BBB, several GSH delivery systems, such as liposomes, nanoparticles, and dendrimers, were developed.

Liposomes are considered as carrier systems for therapeutically active compounds due to their unique characteristics such as capability of incorporating hydrophilic and hydrophobic drugs, good compatibility, low toxicity, lack of immune system activation, and targeted delivery of bioactive compounds to the site of action [91]. Liposome technology has been recently used in the treatment of neurodegenerative diseases. In this context, GSH has been encapsulated in liposomes in order to replenish intracellular GSH and provide neuroprotection in an in vitro model of $\mathrm{PD}$ [92]. The formulation of GSH has been encapsulated in lipid vesicles 
<smiles>CCN[C@@H](CS)C(=O)N[C@@H](Cc1ccc(O)c(O)c1)C(=O)OC</smiles>

9<smiles>CC(=O)C(CS)NC(=O)C(N)Cc1ccc(O)c(O)c1</smiles>

10<smiles>COC(=O)[C@H](Cc1ccc(O)c(O)c1)NC(=O)[C@H](N)CCSC</smiles>

11<smiles>CSCC[C@H](NC(=O)[C@H](N)Cc1ccc(O)c(O)c1)C(C)=O</smiles>

12<smiles>CCCCCC(CS)C(=O)NC(CS)C(=O)NC(Cc1ccc(O)c(O)c1)C(=O)O</smiles>

13<smiles>COC(=O)C(Cc1ccc(O)c(O)c1)NC(=O)C(CS)NC(=O)C(C)(C)S</smiles>

14

Figure 6: Chemical structures of cysteinyl codrugs 9-14.<smiles>[R16][C@H](CS[C@H]1c2c(O)cc(O)cc2O[C@H](c2ccc(O)c(O)c2)[C@H]1[Z19])C(=O)O[Na]</smiles>

$15 \mathrm{R}_{1}=\mathrm{OH}, \mathrm{R}_{2}=\mathrm{H}, \mathrm{R}_{3}=\mathrm{H}$

$16 \mathrm{R}_{1}=\mathrm{Gal}, \mathrm{R}_{2}=\mathrm{H}, \mathrm{R}_{3}=\mathrm{H}$

$17 \mathrm{R}_{1}=\mathrm{OH}, \mathrm{R}_{2}=\mathrm{H}, \mathrm{R}_{3}=\mathrm{Et}$

$18 \mathrm{R}_{1}=\mathrm{Gal}, \mathrm{R}_{2}=\mathrm{H}, \mathrm{R}_{3}=\mathrm{Et}$

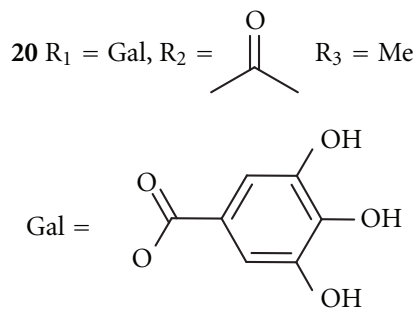

FIgURE 7: Chemical structures of thiol conjugates 15-20.

made of lecithin and glycerol and then tested on mixed mesencephalic cultures treated with paraquat plus maneb. Zeevalk et al. [92] observed that liposomal GSH was taken up into neurons and astrocytes via an endosomal process, and subsequently the endosomes containing liposomal-GSH were fused with lysosomes (Figure 8).

In these conditions, GSH was hydrolyzed and its constituent amino acids (glutamate, cysteine, and glycine) released from lysosomes could be used for the GSH biosynthesis. The results obtained by Zeevalk et al. [92] suggested that this formulation was 100 -fold more potent than nonliposomal-GSH in providing substrates for the maintenance of intracellular GSH in neuronal cells. Moreover, liposomal-GSH dose-dependently provided complete neuroprotection of dopaminergic neurons treated with paraquat plus maneb with an $\mathrm{EC}_{50}$ of $10.5 \mu \mathrm{M} \pm 1.08$. These findings suggest that liposomal-GSH represents a promising therapeutic strategy for neuronal maintenance in pathologies characterized by GSH depletion.

Nanoparticles (NPs) are solid colloidal particles made of polymeric materials ranging in size from $1-1000 \mathrm{~nm}$. NPs are used as carrier systems in which the drug is dissolved, entrapped, encapsulated, adsorbed, or chemically linked to the surface [93]. The advantages of NPs are high drugloading capacity and resistance against chemical and enzymatic degradation. Coating NPs with hydrophilic polymer is a promising strategy in order to prolong their presence in plasma and the therapeutic effect. The surface modification of NPs can be achieved using polyethylene glycol (PEG) or polysaccharides such as chitosan, dextran, pectin, and hyaluronic acid [94, 95]. NPs have been employed for delivering GSH to CNS. In this regard, a series of NPs containing GSH (GS-PEG-GS, 21) were prepared with PEGs of various molecular weights (Figure 9) [96]. PEG was used because of its well-established biocompatibility, low immunogenicity, low antigenicity, and low toxicity [97].

Unfortunately, GS-PEG-GS nanoparticles were not able to exert their antioxidant activity because the thiol groups were consumed during Michael addition. Thus, a disulfide bridge was proposed for antioxidant delivery in order to release GSH when the $\mathrm{pH}$ was low enough to enable thiol formation. Disulfide-linked GSH NPs (GS-SPEGS-SG, 22) were synthesized and tested on SH-SY5Y cells challenged with $100 \mu \mathrm{M} \mathrm{H}_{2} \mathrm{O}_{2}$, a compound that induces oxidative 


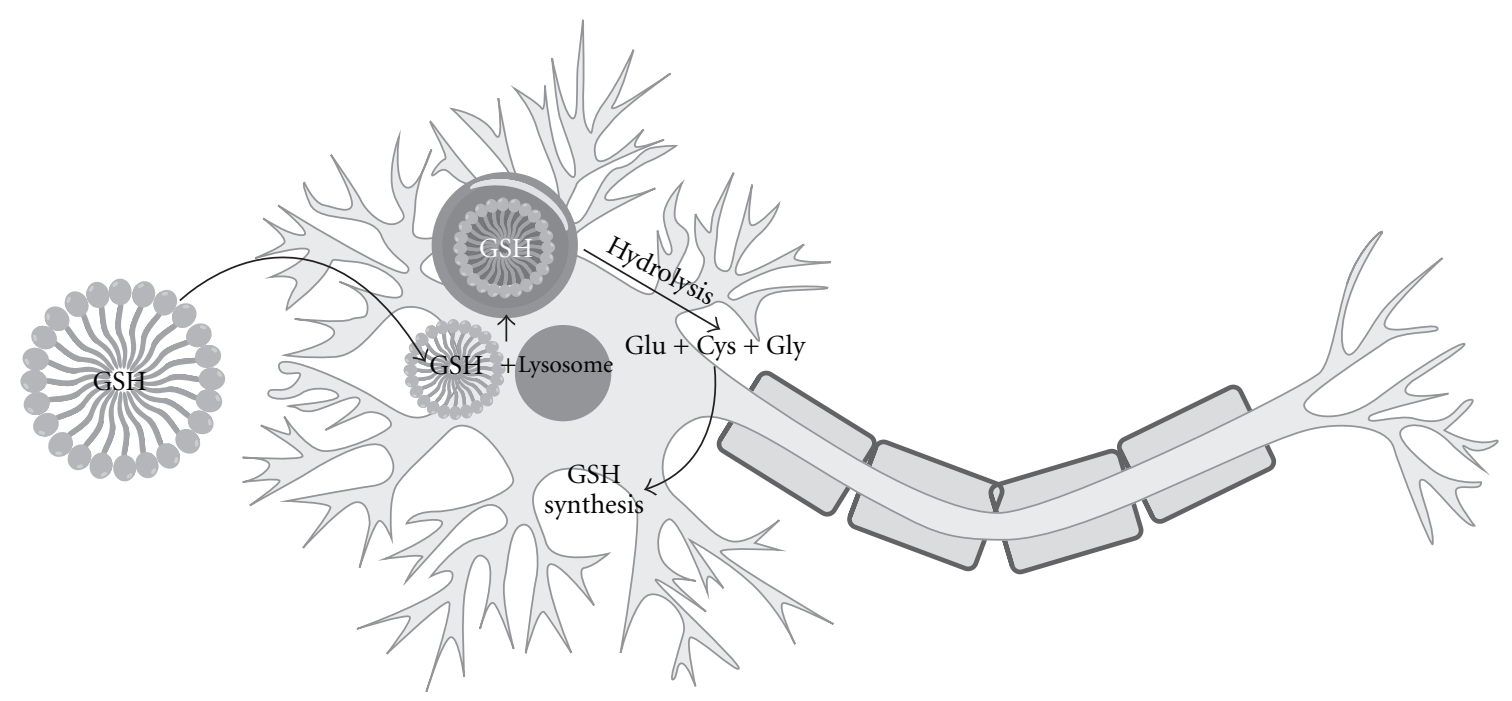

FIGURE 8: Liposomal GSH delivery to neurons and relative hydrolysis following fusion with lysosome.<smiles>CC(C)OC(=O)CCSC[C@H](NC(=O)CC[C@H](N)C(=O)O)C(=O)NCC(=O)OCCOC(=O)CCSC[C@H](NC(=O)CC[C@H](N)C(=O)O)C(=O)NCC(=O)O</smiles>

21<smiles>CCOC(=O)CSSC[C@H](NC(=O)CC[C@H](N)C(=O)O)C(=O)NCC(=O)OCCOC(=O)CSSC[C@H](NC(=O)CC[C@H](N)C(=O)O)C(=O)NCC(=O)O</smiles>

22

Figure 9: Chemical structures of GS-PEG-SG (21) and GS-SPEGS-SG (22).

stress. The GS-SPEGS-SG NPs were 100\% at protecting SHSY5Y cells at $250 \mu \mathrm{M}$ from oxidative stress, while the GSPEG-GS did not offer protection [96]. According to these data, this approach could be employed in treating diseases typically associated with increased ROS levels.

Chitosan-GSH nanoparticles (CS-GSH NPs) have been developed by Koo et al. [98] as delivery system for enhancing stability and bioavailability of GSH. Chitosan (CS) nanodelivery system offers many advantages: (a) it is not toxic; (b) it is biodegradable; (c) it is biocompatible; d) it has good bioadhesibility and water dispersibility $[99,100]$. Thus,
CS-GSH was synthesized using a radical polymerization method, and CS-GSH NPs were prepared by ionic gelation of CS-GSH with sodium tripolyphosphate (TPP) (Figure 10). The resulting NPs showed a good entrapment and loading efficiency. Furthermore, to investigate the CS-GSH NPs stability under oxidative stress, the effect of the presence of $\mathrm{H}_{2} \mathrm{O}_{2}$ on their thiol groups was evaluated. The reduction of thiol groups of the CS-GSH NPs under oxidative stress resulted in being 1.5-fold lower than that of free GSH [98]. These results suggest that CS-GSH NPs could be used as effective delivery carriers of GSH under oxidative insults, but 

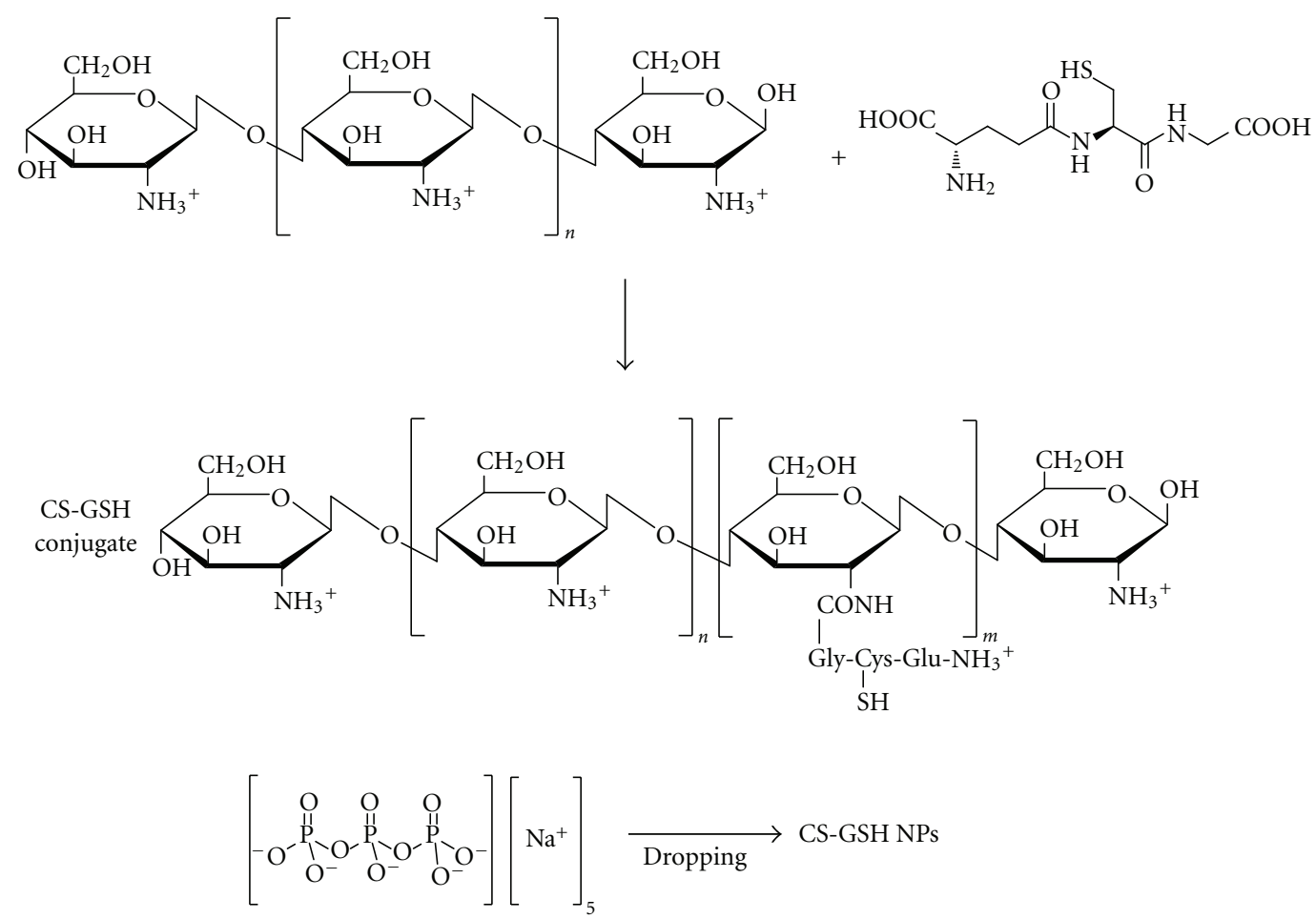

Tripolyphosphate (TPP)

FIGURE 10: Scheme for GS-GSH NPs preparation as reported by Koo et al. [98].

further studies on animal models of $\mathrm{PD}$ and $\mathrm{AD}$ are necessary in order to evaluate their true efficacy.

The use of appropriate nanocarrier systems for GSH may be useful because they are noninvasive systems and protect the molecule to be delivered against inactivation mechanism and clearance. However, they are characterized by limiting factors as safety and toxicity. At present, few data are available about the utilization and human application of nanocarrier systems for transport across the BBB and CNS delivery. Thus, the future clinical study of GSH delivery systems for neurodegenerative diseases is strongly recommended.

\section{Conclusions}

The drug delivery to CNS is a complex and challenging task requiring close collaboration of several scientific areas including pharmaceutical and technological sciences, biological chemistry, and pharmacology. In this context, this paper has investigated multidisciplinary approaches such as the codrug and nanocarriers strategies that could be used to treat neurodegenerative disorders associated with GSH deficiency. GSH and cysteinyl codrugs have been designed on the basis of combining suitable groups of the antioxidant portion with available drugs without altering their inherent pharmacodynamic properties with improved physiochemical properties of drugs. This promising approach has also been used to resolve the issues like permeation, solubility of drug, stability, drug resistance, oral absorption, and brain delivery but still there are very few well-established candidates that have been approved for clinical applications.

Novel experimental neuroprotective strategies include formulations containing GSH, such as nanocarrier systems. This approach could be adopted in order to selectively deliver GSH to tissues in sufficient concentrations to reduce the oxidative damage, but few data are available about clinical studies.

Although the potential use of these strategies needs further exhaustive studies, they may offer a promising therapeutic alternative for reducing the GSH functional loss related to human diseases such as PD and $\mathrm{AD}$.

\section{References}

[1] K. A. Jellinker, "General aspects of neurodegeneration," Journal of Neural Transmission, vol. 65, pp. 101-144, 2003.

[2] K. A. Jellinger, "Basic mechanisms of neurodegeneration: a critical update," Journal of Cellular and Molecular Medicine, vol. 14, no. 3, pp. 457-487, 2010.

[3] M. Valko, D. Leibfritz, J. Moncol, M. T. D. Cronin, M. Mazur, and J. Telser, "Free radicals and antioxidants in normal physiological functions and human disease," International Journal of Biochemistry and Cell Biology, vol. 39, no. 1, pp. 44-84, 2007.

[4] A. Melo, L. Monteiro, R. M. F. Lima, D. M. de Oliveira, M. D. de Cerqueira, and R. S. El-Bacha, "Oxidative stress in neurodegenerative diseases: mechanism and therapeutic perspectives," Oxidative Medicine and Cellular Longevity, vol. 2011, Article ID 467180, 14 pages, 2011. 
[5] W. R. Markesbery, "The role of oxidative stress in Alzheimer disease," Archives of Neurology, vol. 56, no. 12, pp. 1449-1452, 1999.

[6] L. M. Sayre, M. A. Smith, and G. Perry, "Chemistry and biochemistry of oxidative stress in neurodegenerative disease," Current Medicinal Chemistry, vol. 8, no. 7, pp. 721738, 2001.

[7] J. T. Coyle and P. Puttfarcken, "Oxidative stress, glutamate, and neurodegenerative disorders," Science, vol. 262, no. 5134, pp. 689-695, 1993.

[8] P. Jenner, “Oxidative stress in Parkinson's disease," Annals of Neurology, vol. 53, supplement 3, pp. S26-S38, 2003.

[9] M. C. Polidori, H. R. Griffiths, E. Mariani, and P. Mecocci, "Hallmarks of protein oxidative damage in neurodegenerative diseases: focus on Alzheimer's disease," Amino Acids, vol. 32, no. 4, pp. 553-559, 2007.

[10] P. I. Moreira, K. Honda, L. Quan et al., "Alzheimer's disease and oxidative stress: the old problem remains unsolved," Current Medicinal Chemistry, vol. 5, no. 1, pp. 51-62, 2005.

[11] T. Farooqui and A. A. Farooqui, "Aging: an important factor for the pathogenesis of neurodegenerative diseases," Mechanisms of Ageing and Development, vol. 130, no. 4, pp. 203-215, 2009.

[12] S. Fahn and G. Cohen, "The oxidant stress hypothesis in Parkinson's disease: evidence supporting it," Annals of Neurology, vol. 32, no. 6, pp. 804-812, 1992.

[13] D. Offen, S. Gorodin, E. Melamed, J. Hanania, and Z. Malik, "Dopamine-melanin is actively phagocytized by PC12 cells and cerebellar granular cells: possible implications for the etiology of Parkinson's disease," Neuroscience Letters, vol. 260, no. 2, pp. 101-104, 1999.

[14] J. B. Schulz, J. Lindenau, J. Seyfried, and J. Dichgans, "Glutathione, oxidative stress and neurodegeneration," European Journal of Biochemistry, vol. 267, no. 16, pp. 4904-4911, 2000.

[15] J. S. Bains and C. A. Shaw, "Neurodegenerative disorders in humans: the role of glutathione in oxidative stress-mediated neuronal death," Brain Research Reviews, vol. 25, no. 3, pp. 335-358, 1997.

[16] M. Lee, T. Cho, N. Jantaratnotai, Y. T. Wang, E. McGeer, and P. L. McGeer, "Depletion of GSH in glial cells induces neurotoxicity: relevance to aging and degenerative neurological diseases," The FASEB Journal, vol. 24, no. 7, pp. 2533-2545, 2010.

[17] R. K. B. Pearce, A. Owen, S. Daniel, P. Jenner, and C. D. Marsden, "Alterations in the distribution of glutathione in the substantia nigra in Parkinson's disease," Journal of Neural Transmission, vol. 104, no. 6-7, pp. 661-677, 1997.

[18] J. Sian, D. T. Dexter, A. J. Lees et al., "Alterations in glutathione levels in Parkinson's disease and other neurodegenerative disorders affecting basal ganglia," Annals of Neurology, vol. 36, no. 3, pp. 348-355, 1994.

[19] P. Damier, E. C. Hirsch, P. Zhang, Y. Agid, and F. Javoy-Agid, "Glutathione peroxidase, glial cells and Parkinson's disease," Neuroscience, vol. 52, no. 1, pp. 1-6, 1993.

[20] M. Garrido, Y. Tereshchenko, Z. Zhevtsova, G. Taschenberger, M. Bähr, and S. Kügler, "Glutathione depletion and overproduction both initiate degeneration of nigral dopaminergic neurons," Acta Neuropathologica, vol. 121, no. 4, pp. 475-485, 2011.

[21] D. S. Albers and M. F. Beal, "Mitochondrial dysfunction and oxidative stress in aging and neurodegenerative disease," Journal of Neural Transmission, no. 59, pp. 133-154, 2000.
[22] P. Jenner, "Oxidative mechanisms in nigral cell death in Parkinson's disease," Movement Disorders, vol. 13, no. 1, pp. 24-34, 1998.

[23] J. P. E. Spencer, P. Jenner, S. E. Daniel, A. J. Lees, D. C. Marsden, and B. Halliwell, "Conjugates of catecholamines with cysteine and GSH in Parkinson's disease: possible mechanisms of formation involving reactive oxygen species," Journal of Neurochemistry, vol. 71, no. 5, pp. 2112-2122, 1998.

[24] J. K. Andersen, J. Q. Mo, D. G. Horn et al., "Effect of buthionine sulfoximine, a synthesis inhibitor of the antioxidant glutathione, on the murine nigrostriatal neurons," Journal of Neurochemistry, vol. 67, no. 5, pp. 2164-2171, 1996.

[25] M. T. Lin and M. F. Beal, "Mitochondrial dysfunction and oxidative stress in neurodegenerative diseases," Nature, vol. 443, no. 7113, pp. 787-795, 2006.

[26] S. J. Chinta and J. K. Andersen, "Reversible inhibition of mitochondrial complex I activity following chronic dopaminergic glutathione depletion in vitro: implications for Parkinson's disease," Free Radical Biology and Medicine, vol. 41, no. 9, pp. 1442-1448, 2006.

[27] S. J. Chinta, M. J. Kumar, M. Hsu et al., "Inducible alterations of glutathione levels in adult dopaminergic midbrain neurons result in nigrostriatal degeneration," Journal of Neuroscience, vol. 27, no. 51, pp. 13997-14006, 2007.

[28] L. F. Lau and M. A. Brodney, "Therapeutic approaches for the treatment of Alzheimer's disease: an overview," Topics in Medicinal Chemistry, vol. 2, pp. 1-24, 2008.

[29] S. Varadarajan, S. Yatin, M. Aksenova, and D. A. Butterfield, "Review: Alzheimer's amyloid $\beta$-peptide-associated free radical oxidative stress and neurotoxicity," Journal of Structural Biology, vol. 130, no. 2-3, pp. 184-208, 2000.

[30] A. V. Maltsev, S. Bystryak, and O. V. Galzitskaya, "The role of $\beta$-amyloid peptide in neurodegenerative diseases," Ageing Research Reviews, vol. 10, pp. 440-452, 2011.

[31] M. Gu, A. D. Owen, S. E. K. Toffa et al., "Mitochondrial function, GSH and iron in neurodegeneration and Lewy body diseases," Journal of the Neurological Sciences, vol. 158, no. 1, pp. 24-29, 1998.

[32] H. Liu, L. E. Harrell, S. Shenvi, T. Hagen, and R. M. Liu, "Gender differences in glutathione metabolism in Alzheimer's disease," Journal of Neuroscience Research, vol. 79, no. 6, pp. 861-867, 2005.

[33] J. D. Adams, L. K. Klaidman, I. N. Odunze, H. C. Shen, and C. A. Miller, "Alzheimer's and Parkinson's disease: brain levels of glutathione, glutathione disulfide, and vitamin E," Molecular and Chemical Neuropathology, vol. 14, no. 3, pp. 213-226, 1991.

[34] T. L. Perry, V. W. Yong, C. Bergeron, S. Hansen, and K. Jones, "Amino acids, glutathione, and glutathione transferase activity in the brains of patients with Alzheimer's disease," Annals of Neurology, vol. 21, no. 4, pp. 331-336, 2005.

[35] R. J. Mark, M. A. Lovell, W. R. Markesbery, K. Uchida, and M. P. Mattson, "A role for 4-hydroxynonenal, an aldehydic product of lipid peroxidation, in disruption of ion homeostasis and neuronal death induced by amyloid $\beta$ - peptide," Journal of Neurochemistry, vol. 68, no. 1, pp. 255-264, 1997.

[36] D. A. Butterfield, C. B. Pocernich, and J. Drake, "Elevated glutathione as a therapeutic strategy in Alzheimer's disease," Drug Development Research, vol. 56, no. 3, pp. 428-437, 2002.

[37] C. L. Hammond, T. K. Lee, and N. Ballatori, "Novel roles for glutathione in gene expression, cell death, and membrane transport of organic solutes," Journal of Hepatology, vol. 34, no. 6, pp. 946-954, 2001. 
[38] N. Ghosh, R. Ghosh, and S. C. Mandal, "Antioxidant protection: a promising therapeutic intervention in neurodegenerative disease," Free Radical Research, vol. 45, no. 8, pp. 888-905, 2011.

[39] V. di Matteo and E. Esposito, "Biochemical and therapeutic effects of antioxidants in the treatment of Alzheimer's disease, Parkinson's disease, and amyotrophic lateral sclerosis," Current Drug Targets, CNS \& Neurological Disorders, vol. 2, no. 2, pp. 95-107, 2003.

[40] I. Cacciatore, C. Cornacchia, L. Baldassarre et al., "GPE and GPE analogues as promising neuroprotective agents," Mini Reviews in Medicinal Chemistry, vol. 12, no. 1, pp. 13-23, 2012.

[41] C. Cornacchia, I. Cacciatore, L. Baldassarre, A. Mollica, F. Feliciani, and F. Pinnen, "2,5-Diketopiperazines as neuroprotective agents," Mini Reviews in Medicinal Chemistry, vol. 12, pp. 2-12, 2012.

[42] B. Moosmann and C. Behl, "Antioxidants as treatment for neurodegenerative disorders," Expert Opinion on Investigational Drugs, vol. 11, no. 10, pp. 1407-1435, 2002.

[43] R. Dringen, "Metabolism and functions of glutathione in brain," Progress in Neurobiology, vol. 62, no. 6, pp. 649-671, 2000.

[44] R. Dringen and J. Hirrlinger, "Glutathione pathways in the brain,” Biological Chemistry, vol. 384, no. 4, pp. 505-516, 2003.

[45] J. S. Bains and C. A. Shaw, "Neurodegenerative disorders in humans: the role of glutathione in oxidative stress-mediated neuronal death," Brain Research Reviews, vol. 25, no. 3, pp. 335-358, 1997.

[46] D. M. Townsend, K. D. Tew, and H. Tapiero, "The importance of glutathione in human disease," Biomedicine and Pharmacotherapy, vol. 57, no. 3, pp. 145-155, 2003.

[47] N. Ballatori, S. M. Krance, S. Notenboom, S. Shi, K. Tieu, and C. L. Hammond, "Glutathione dysregulation and the etiology and progression of human diseases," Biological Chemistry, vol. 390, no. 3, pp. 191-214, 2009.

[48] H. L. Martin and P. Teismann, "Glutathione-a review on its role and significance in Parkinson's dysregulation and the etiology and progression of human diseases," The FASEB Journal, vol. 23, pp. 3263-3272, 2009.

[49] I. Guidi, D. Galimberti, S. Lonati et al., "Oxidative imbalance in patients with mild cognitive impairment and Alzheimer's disease," Neurobiology of Aging, vol. 27, no. 2, pp. 262-269, 2006.

[50] M. Dumont and M. F. Beal, "Neuroprotective strategies involving ROS in Alzheimer disease," Free Radical Biology and Medicine, vol. 51, pp. 1014-1026, 2011.

[51] M. J. Mcmanus, M. P. Murphy, and J. L. Franklin, "The mitochondria-targeted antioxidant mitoq prevents loss of spatial memory retention and early neuropathology in a transgenic mouse model of Alzheimer's disease," The Journal of Neuroscience, vol. 31, pp. 15703-15715, 2011.

[52] J. S. Beckman, A. G. Estévez, J. P. Crow, and L. Barbeito, "Superoxide dismutase and the death of motoneurons in ALS," Trends in Neurosciences, vol. 24, supplement 11, pp. S15-S20, 2001.

[53] M. R. Vargas, D. A. Johnson, and J. A. Johnson, "Decreased glutathione accelerates neurologiCal deficit and mitochondrial pathology in familial ALS-linked hSOD1 $1^{\mathrm{G} 93 \mathrm{~A}}$ mice model," Neurobiology of Disease, vol. 43, no. 3, pp. 543-551, 2011.

[54] C. Behl and B. Moosmann, "Antioxidant neuroprotection in Alzheimer's disease as preventive and therapeutic approach,"
Free Radical Biology and Medicine, vol. 33, no. 2, pp. 182-191, 2002.

[55] G. D. Zeevalk, L. Manzino, P. K. Sonsalla, and L. P. Bernard, "Characterization of intracellular elevation of glutathione (GSH) with glutathione monoethyl ester and GSH in brain and neuronal cultures: relevance to Parkinson's disease," Experimental Neurology, vol. 203, no. 2, pp. 512-520, 2007.

[56] I. Cacciatore, C. Cornacchia, F. Pinnen, A. Mollica, and A. di Stefano, "Prodrug approach for increasing cellular glutathione levels," Molecules, vol. 15, no. 3, pp. 1242-1264, 2010.

[57] I. Cacciatore, A. Cocco, M. Costa et al., "Biochemical properties of new synthetic carnosine analogues containing the residue of 2,3-diaminopropionic acid: the effect of $\mathrm{N}$ acetylation," Amino Acids, vol. 28, no. 1, pp. 77-83, 2005.

[58] L. Brunetti, I. Cacciatore, A. di Stefano et al., "Synthesis and biological evaluation of a novel pyroglutamyl-modified TRH analogue," Farmaco, vol. 57, no. 6, pp. 479-486, 2002.

[59] N. Denora, A. Trapani, V. Laquintana, A. Lopedota, and G. Trapani, "Recent advances in medicinal chemistry and pharmaceutical technology-strategies for drug delivery to the brain," Current Topics in Medicinal Chemistry, vol. 9, no. 2, pp. 182-196, 2009.

[60] I. Cacciatore, A. di Stefano, G. Luisi, F. Pinnen, and P. Sozio, "Transition state isosteres of the $\gamma$-glutamyl peptide bond hydrolysis: synthesis and characterization of the $\psi\left(\mathrm{CH}_{2} \mathrm{NH}\right)$ pseudopeptide analogue of glutathione," Journal of Peptide Science, vol. 10, no. 2, pp. 109-114, 2004.

[61] I. Cacciatore, A. M. Caccuri, A. di Stefano et al., "Synthesis and activity of novel glutathione analogues containing an urethane backbone linkage," Farmaco, vol. 58, no. 9, pp. 787793, 2003.

[62] I. Cacciatore, A. M. Caccuri, A. Cocco et al., "Potent isozymeselective inhibition of human glutathione S-transferase A1-1 by a novel glutathione S-conjugate," Amino Acids, vol. 29, no. 3, pp. 255-261, 2005.

[63] N. Das, M. Dhanawat, B. Dash, R. C. Nagarwal, and S. K. Shrivastava, "Codrug: an efficient approach for drug optimization," European Journal of Pharmaceutical Sciences, vol. 41, no. 5, pp. 571-588, 2010.

[64] M. Decker, "Hybrid molecules incorporating natural products: applications in cancer therapy, neurodegenerative disorders and beyond," Current Medicinal Chemistry, vol. 18, no. 10, pp. 1464-1475, 2011.

[65] A. Minelli, C. Conte, I. Cacciatore, C. Cornacchia, and F. Pinnen, "Molecular mechanism underlying the cerebral effect of Gly-Pro-Glu tripeptide bound to L-dopa in a Parkinson's animal model," Amino Acids. In press.

[66] P. Sozio, A. Iannitelli, L. S. Cerasa et al., "New L-dopa codrugs as potential antiparkinson agents," Archiv der Pharmazie, vol. 341, no. 7, pp. 412-417, 2008.

[67] M. Malakoutikhah, M. Teixidó, and E. Giralt, "Toward an optimal blood-brain barrier shuttle by synthesis and evaluation of peptide libraries," Journal of Medicinal Chemistry, vol. 51, no. 16, pp. 4881-4889, 2008.

[68] R. Kannan, J. F. Kuhlenkamp, E. Jeandidier, H. Trinh, M. Ookhtens, and N. Kaplowitz, "Evidence for carrier-mediated transport of glutathione across the blood-brain barrier in the rat," Journal of Clinical Investigation, vol. 85, no. 6, pp. 20092013, 1990 .

[69] F. Pinnen, I. Cacciatore, C. Cornacchia et al., "Synthesis and study of L-dopa-glutathione codrugs as new anti-Parkinson agents with free radical scavenging properties," Journal of Medicinal Chemistry, vol. 50, no. 10, pp. 2506-2515, 2007. 
[70] S. S. More and R. Vince, "Design, synthesis and biological evaluation of glutathione peptidomimetics as components of anti-Parkinson prodrugs," Journal of Medicinal Chemistry, vol. 51, no. 15, pp. 4581-4588, 2008.

[71] U. Bickel, Y. S. Kang, and W. M. Pardridge, "In vivo cleavability of a disulfide-based chimeric opioid peptide in rat brain," Bioconjugate Chemistry, vol. 6, no. 2, pp. 211-218, 1995.

[72] F. Pinnen, I. Cacciatore, C. Cornacchia et al., "CNS delivery of 1-dopa by a new hybrid glutathione-methionine peptidomimetic prodrug," Amino Acids, vol. 42, no. 1, pp. 261$269,2012$.

[73] K. Ehrlich, S. Viirlaid, R. Mahlapuu et al., "Design, synthesis and properties of novel powerful antioxidants, glutathione analogues," Free Radical Research, vol. 41, no. 7, pp. 779-787, 2007.

[74] K. Ehrlich, K. Ida, R. Mahlapuu et al., "Characterization of UPF peptides, members of the glutathione analogues library, on the basis of their effects on oxidative stress-related enzymes," Free Radical Research, vol. 43, no. 6, pp. 572-580, 2009.

[75] P. Põder, M. Zilmer, J. Starkopf et al., "An antioxidant tetrapeptide UPF1 in rats has a neuroprotective effect in transient global brain ischemia," Neuroscience Letters, vol. 370, no. 1, pp. 45-50, 2004.

[76] E. Karelson, R. Mahlapuu, M. Zilmer, U. Soomets, N. Bogdanovic, and Ü Langel, "Possible signaling by glutathione and its novel analogue through potent stimulation of frontocortical G proteins in normal aging and in Alzheimer's disease," Annals of the New York Academy of Sciences, vol. 973, pp. 537-540, 2002.

[77] F. Pinnen, P. Sozio, I. Cacciatore et al., "Ibuprofen and glutathione conjugate as a potential therapeutic agent for treating Alzheimer's disease," Archiv der Pharmazie, vol. 344, no. 3, pp. 139-148, 2011.

[78] K. N. Prasad, W. C. Cole, and K. C. Prasad, "Risk factors for Alzheimer's disease: role of multiple antioxidants, nonsteroidal anti-inflammatory and cholinergic agents alone or in combination in prevention and treatment," Journal of the American College of Nutrition, vol. 21, no. 6, pp. 506-522, 2002.

[79] G. P. Lim, F. Yang, T. Chu et al., "Ibuprofen suppresses plaque pathology and inflammation in a mouse model for Alzheimer's disease," Journal of Neuroscience, vol. 20, no. 15, pp. 5709-5714, 2000.

[80] Q. Yan, J. Zhang, H. Liu et al., "Anti-inflammatory drug therapy alters $\beta$-amyloid processing and deposition in an animal model of Alzheimer's disease," Journal of Neuroscience, vol. 23, no. 20, pp. 7504-7509, 2003.

[81] G. Atmaca, "Antioxidant effects of sulfur-containing amino acids," Yonsei Medical Journal, vol. 45, no. 5, pp. 776-788, 2004.

[82] F. Pinnen, I. Cacciatore, C. Cornacchia et al., "Codrugs linking L-dopa and sulfur-containing antioxidants: new pharmacological tools against Parkinson's disease," Journal of Medicinal Chemistry, vol. 52, no. 2, pp. 559-563, 2009.

[83] D. Offen, I. Ziv, H. Sternin, E. Melamed, and A. Hochman, "Prevention of dopamine-induced cell death by thiol antioxidants: possible implications for treatment of Parkinson's disease," Experimental Neurology, vol. 141, no. 1, pp. 32-39, 1996.

[84] A. Minelli, C. Conte, E. Prudenzi et al., "N-Acetyl-L-Methionyl-L-Dopa-Methyl Ester as a dual acting drug that relieves L-Dopa-induced oxidative toxicity," Free Radical Biology and Medicine, vol. 49, no. 1, pp. 31-39, 2010.
[85] J. L. Torres, C. Lozano, and P. Maher, "Conjugation of catechins with cysteine generates antioxidant compounds with enhanced neuroprotective activity," Phytochemistry, vol. 66, no. 17, pp. 2032-2037, 2005.

[86] P. Maher, J. Lewerenz, C. Lozano, and J. L. Torres, "A novel approach to enhancing cellular glutathione levels," Journal of Neurochemistry, vol. 107, no. 3, pp. 690-700, 2008.

[87] H. Sato, M. Tamba, T. Ishii, and S. Bannai, "Cloning and expression of a plasma membrane cystine/glutamate exchange transporter composed of two distinct proteins," Journal of Biological Chemistry, vol. 274, no. 17, pp. 1145511458, 1999.

[88] S. R. Steinhubl, "Why have antioxidants failed in clinical trials?" American Journal of Cardiology, vol. 101, supplement 10, pp. S14-S19, 2008.

[89] D. V. Ratnam, D. D. Ankola, V. Bhardwaj, D. K. Sahana, and M. N. V. R. Kumar, "Role of antioxidants in prophylaxis and therapy: a pharmaceutical perspective," Journal of Controlled Release, vol. 113, no. 3, pp. 189-207, 2006.

[90] J. L. Gilmore, X. Yi, L. Quan, and A. V. Kabanov, "Novel nanomaterials for clinical neuroscience," Journal of NeuroImmune Pharmacology, vol. 3, no. 2, pp. 83-94, 2008.

[91] C. Chen, D. Han, C. Cai, and X. Tang, "An overview of liposome lyophilization and its future potential," Journal of Controlled Release, vol. 142, no. 3, pp. 299-311, 2010.

[92] G. D. Zeevalk, L. P. Bernard, and F. T. Guilford, "Liposomalglutathione provides maintenance of intracellular glutathione and neuroprotection in mesencephalic neuronal cells," Neurochemical Research, vol. 35, no. 10, pp. 1575-1587, 2010.

[93] W. H. de Jong and P. J. A. Borm, "Drug delivery and nanoparticles: applications and hazards," International Journal of Nanomedicine, vol. 3, no. 2, pp. 133-149, 2008.

[94] A. Aumelas, A. Serrero, A. Durand, E. Dellacherie, and M. Leonard, "Nanoparticles of hydrophobically modified dextrans as potential drug carrier systems," Colloids and Surfaces B, vol. 59, no. 1, pp. 74-80, 2007.

[95] F. Esmaeili, M. H. Ghahremani, B. Esmaeili, M. R. Khoshayand, F. Atyabi, and R. Dinarvand, "PLGA nanoparticles of different surface properties: preparation and evaluation of their body distribution," International Journal of Pharmaceutics, vol. 349, no. 1-2, pp. 249-255, 2008.

[96] S. R. Williams, B. S. Lepene, C. D. Thatcher, and T. E. Long, "Synthesis and characterization of poly(ethylene glycol)-glutathione conjugate self-assembled nanoparticles for antioxidant delivery," Biomacromolecules, vol. 10, no. 1, pp. 155-161, 2009.

[97] N. A. Alcantar, E. S. Aydil, and J. N. Israelachvili, "Polyethylene glycol-coated biocompatible surfaces," Journal of Biomedical Materials Research, vol. 51, no. 3, pp. 343-351, 2000.

[98] S. H. Koo, J. S. Lee, G. H. Kim, and H. G. Lee, "Preparation, characteristics, and stability of glutathione-loaded nanoparticles," Journal of Agricultural and Food Chemistry, vol. 9, pp. 11264-11269, 2011.

[99] S. A. Agnihotri, N. N. Mallikarjuna, and T. M. Aminabhavi, "Recent advances on chitosan-based micro- and nanoparticles in drug delivery," Journal of Controlled Release, vol. 100, no. 1, pp. 5-28, 2004.

[100] H. Takeuchi, H. Yamamoto, and Y. Kawashima, "Mucoadhesive nanoparticulate systems for peptide drug delivery," Advanced Drug Delivery Reviews, vol. 47, no. 1, pp. 39-54, 2001. 


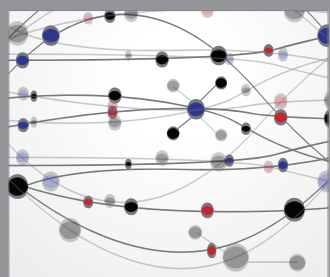

The Scientific World Journal
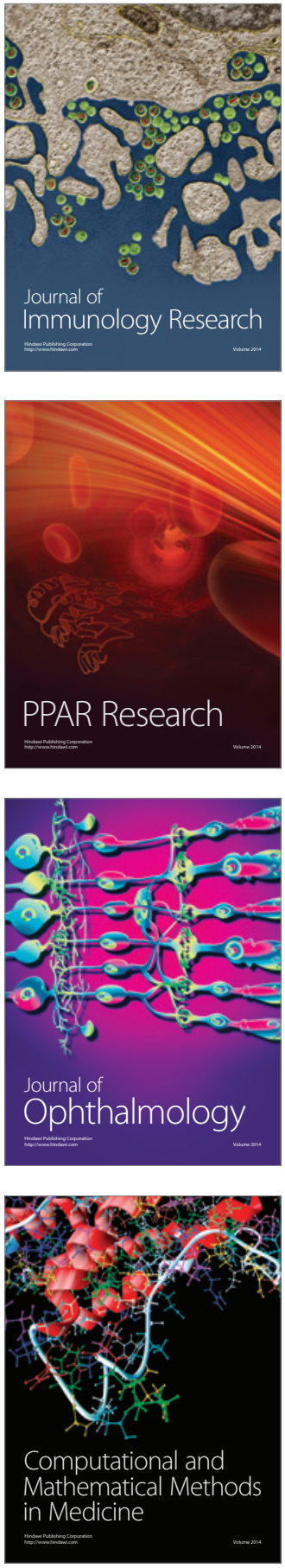

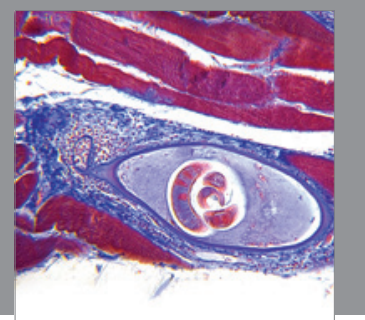

Gastroenterology

Research and Practice
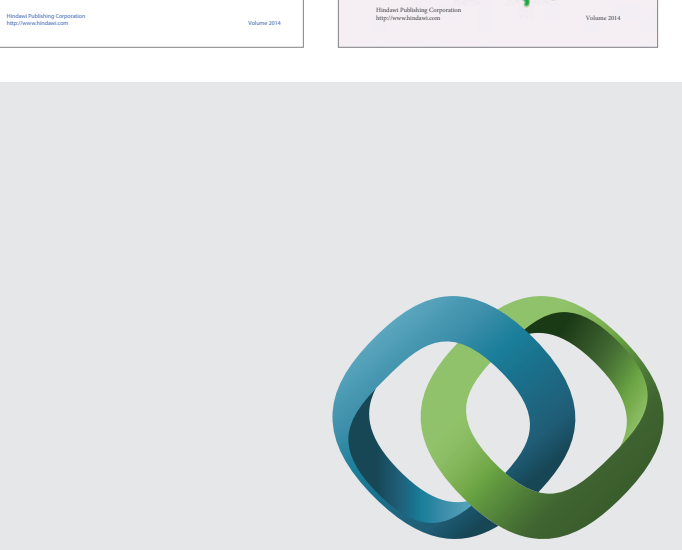

\section{Hindawi}

Submit your manuscripts at

http://www.hindawi.com
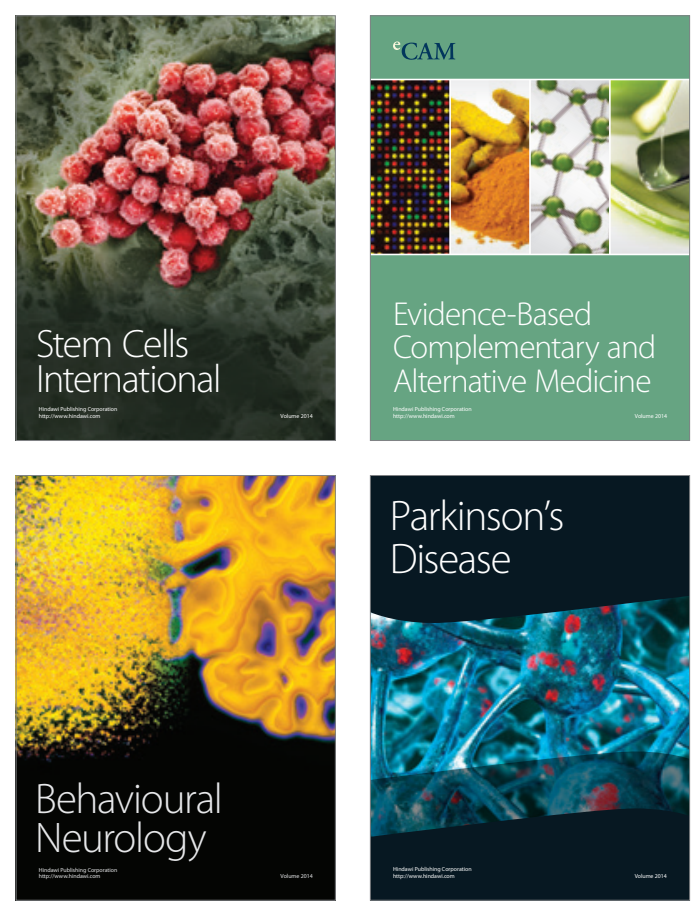

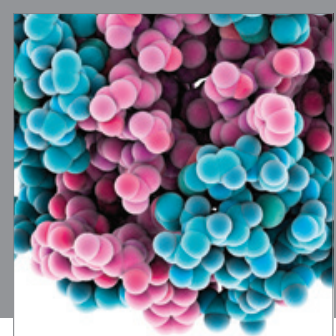

Journal of
Diabetes Research

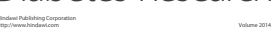

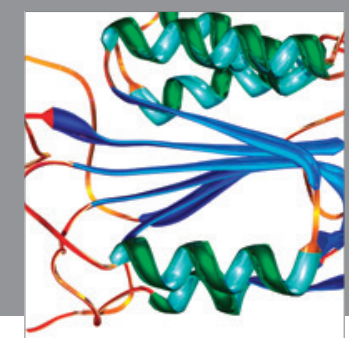

Disease Markers
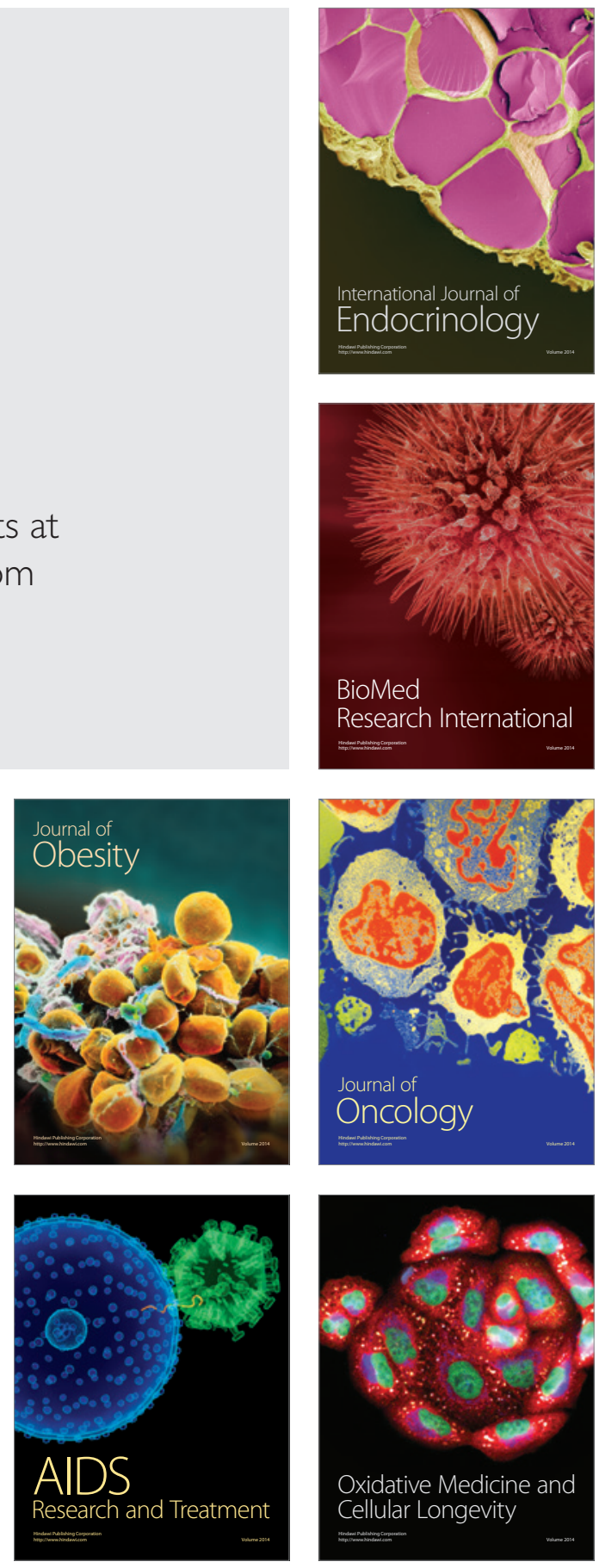